\title{
Determinants of women's health in Europe: using large open data collections to unveil the hidden part of the iceberg
}

\section{By Lourdes Cantarero-Arévalo}

\section{Abstract}

Open data collections can be powerful, providing democratic tools to illustrate women's health across Europe. This article discusses the benefits offered by the large volume of open-access data in comparison with access-restrictive big data, and provides an overview of the main databases publically available which gather sex-disaggregated data information, as well as of their strengths and limitations (The World Health Organization European Health for All database, EUROSTAT, Institute for Health Metrics and Evaluation - Global Burden of Disease data and OECD data). Examples are provided to illustrate the outcomes that can be obtained from the different databases, with special emphasis on the socioeconomic determinants of women's health (education, income and wealth, employment and place of residence) in the European Region. Open online data collections accessible to all can be used as tools to argue in favour of not only the implementation of health-care policies, but also social and economic policies aimed at improving women's health in Europe. However, open-access online data collections have certain drawbacks worth considering such as the need for continuous monitoring and updating, ensuring the reliability of data provided by all countries, and guaranteeing that individuals cannot be identified through links between clinical and socioeconomic data.

\section{KEYWORDS}

\section{Quantitative methods, open-access data, women's health, social determinants, Europe}

Lourdes Cantarero-Arévalo is Assistant Professor of Social and Clinical Pharmacy at the Faculty of Health and Medical Sciences, University of Copenhagen. 


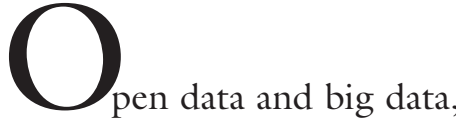
although closely related, are not quite the same: big data is defined by its size, whereas open data is defined by its use (Gurin 2016). Big data is the term used to describe very large, complex, rapidly changing datasets. Big data, Hilbert argues (2016), is expected to bring significant benefits to health and health care, as it has to other sections of the economy. Open data is accessible public data that people, companies and organisations can use to analyse patterns and trends, make data-driven decisions and solve complex problems. All definitions of open data include two basic features: the data must be publicly available for anyone to use, and it must be licensed in a way that allows for its reuse. Open data should also be relatively easy to use not only by researchers and professionals, but also by minority- and gender-serving institutions, such as non-governmental organizations, although there are gradations of 'openness'. Also there is general agreement among academic, third-sector, public and private institutions that open data should be available free of charge or at minimal cost (Zhang 2017).

A key advantage of big data analytics is its linking of disparate data sources, which requires access to personal identifiable information, or at least some proxy (Mittelstadt \& Floridi 2016), and this poses privacy and ethics concerns. Access to big data is therefore constrained to large research institutions, making it difficult for resource-limited third-sector institutions to access and use such data. Big data includes all kinds of data that are kept from the public. For example, registers from Nordic countries contain information on place of birth and ancestry that can only be accessed after authorization by Statistics Denmark and justified by a sound research proposal (Cantarero-Arévalo et al. 2014). This kind of big data gives an advantage to those who control it, but it may disempower the rest of us. It is this kind of big data that has become most controversial. Conversely, open data, although not necessarily big, also can have a big impact, especially when it is made public. Data from local governments that are available and accessible (i.e. there are no costs for accessing it), for example, can help informed citizens participate in local budgeting, choose health care or analyse the quality of local services, given the right participatory mechanisms.

Open-access data are often collected by public national institutions that afterwards transfer the sex disaggregated data to multilateral organizations such as the EC or UN agencies. The data are quality-controlled by both the country and the multilateral organization and are available to the general public. These data do not relate to individuals, and therefore ethical considerations regarding the identification of personal information do not apply. A drawback is therefore the impossibility of linking clinical data with socioeconomic and sociodemographic data.

On the twentieth anniversary of the commitments of the Beijing Platform for Action and the Programme of Action of the International Conference for Population and Development, the WHO Regional Office for Europe initiated development of a Regional Strategy on Women's Health during 2015-2016 (WHO 2015). The strategy was informed by qualitative analyses of the available data and literature, which relied substantially on access to and use of open-access sex- and age-disaggregated data (see Methods).

The purpose of this article is therefore twofold: first, to make the case for the collection and use of open-access sex- and age-disaggregated data for the European region compared to restrictive big data; and secondly, to illustrate the potential of the collection, analysis and use of large sex- 
and age-disaggregated open-access data when designing gender-informed policies for women's health across the life-course with a special focus on socioeconomic determinants in 53 European countries.

The data included in this study have principally been extracted from large opendatabases from WHO databases: the European Health for All database (HFA-DB), the Institute for Health Metrics and Evaluation (IHME), the European Commission's Eurostat Directorate-General (Eurostat) and the Organization for Economic Cooperation and Development (OECD). A brief description of the main databases consulted is included in Table 1.

\section{OPEN SEX-DISAGGREGATED DATA:}

\section{A DEMOCRATIC TOOL FOR POLICY-}

\section{MAKING IN GENDER AND HEALTH}

Since the Beijing Declaration and Platform for Action on Women in 1994, efforts to improve women's health and reduce gender inequalities in health have faced challenges. These have arisen not least in the collection and use of data disaggregated by sex and age, which could be used to strengthen policy and programme development for women's health and well-being over the life course and with attention to inequalities. Systematics and meta-analyses often make use of quantitative studies to, among others, shape and improve healthcare guidelines, an important component of evidence-informed policy and programmed development. Since 1997, all United Nations agencies, including the World Health Organization (WHO), have been required to undertake gender mainstreaming, a globally accepted strategy for promoting gender equality. Mainstreaming is not an end in itself but a strategy, an approach, a means to achieve the goal of gender equality. It involves ensuring that gender perspectives and attention to the goal of gender equality are central to all activities, such as policy development, research, advocacy/dialogue, legislation, resource allocation, and planning, and the implementation and monitoring of programmes and projects. Improving and ensuring the systematic collection, analysis and use of sexand age-disaggregated data is an important component of gender mainstreaming (UN Women 2016). The WHO, aware of the problem that a lack of sex-disaggregated data implies, conducts regular genderawareness actions with ministries of health in its member states (hereafter referred to as countries) around the world to improve and promote the systematic collection, analysis and use of sex-disaggregated data that are openly available.

The majority of the countries belonging to the WHO's European region ${ }^{1}$ have a wealth of publicly available sex-disaggregated data that can be cross-linked with social determinants to obtain a more comprehensive picture of women's health and potential inequalities among women. This allows more informed decision-making in the field of gender and health. Currently, the majority of the WHO's European region countries use these sex-disaggregated data to implement, monitor and evaluate programs, for example, to reduce gender-based violence, to improve the detection and diagnosis of cardiovascular diseases, or to improve access to primary and secondary education for young and adolescent girls and young women. (Cantarero-Arévalo et al. 2011).

Despite persisting limitations in the collection of sex-disaggregated data, such as the level of complexity and granularity, or the lack of international common standards (Data2x.org 2017), access to open data has great potential to reveal with ever-increasing precision inequalities in health not only between men and women, but also inequalities among women between and within countries. Compared with big data, open data allow transparent and democratic access to data, often through the internet, thus making it available for local, regional 
and national governments, as well as private entities. In this context, a lack of sex-disaggregated data can no longer be used as an excuse for inaction on gender inequalities, or even inequalities among women. Having reliable sex-disaggregated data is a necessary pre-condition for informing action on gender inequalities, but it is not enough on its own because it only highlights differences between females and males. Gender analysis of the data is essential to determine whether the inequalities stem from gender norms, roles and relations, or unequal power relations between and among men and women, as well as the intersection of these differences with other contextual factors such as ethnicity, education, or employment status (WHO 2011). An example is the global Equal pay for work of equal value campaign by UN Women (UN WOMEN 2017a), which highlights differences among men and women and among women globally and/or in different professions. The conditions for conducting a proper gender analysis include, an enabling policy and institutional environment, ways of ensuring the quality, comparability and regularity of data production, and facilitating the accessibility and use of the data to all in order to inform policy (UN WOMEN 2017b).

\section{Methodological Approach}

A review of open-data sets in 2015 was conducted to substantiate the development of a report on women's health and well-being across the life-course in the WHO European region with a focus on social determinants and inequalities in health. In the following sections, selected parts of this analysis are presented, including the reviews of open-data sets which were included in the report produced for the WHO (WHO 1015), referred to above. Given the breadth of health issues that could be considered, a review of the Institute for Health Metrics Evaluation (IHME) database was undertaken (in February 2015) to identify the broad causes of Disability Adjusted Life Years (DALYs) ${ }^{2}$ and mortality within the region for the four to five age-stages. This was then used to identify additional openaccess databases that could be used, and to refine the focus of data collection and the literature reviews in terms of 'health' topics covered. However, due to the limited availability of age- and sex-disaggregated data for all 53 member states, sometimes a reduced sample of countries was included when cross-linking these data with sex, age and other key social determinants such as education, residence and employment.

Despite their tremendous potential for informing gender-sensitive policies, trying to analysis data for all 53 countries does pose certain challenges. Data available through Eurostat databases are the most up to date and reliable but they do not contain data for all 53 countries, and it is often the case that data is missing for the more vulnerable countries. Another challenge is that not all the national databases are updated at the same pace. For example, the WHO Health for All database is updated twice a year, whereas Eurostat is updated almost daily. The limitation is therefore that only a selected set of health topics were covered in detail when in some countries in the region a particular health condition might make a much greater contribution to women's mortality or morbidity than in others, for example, HIVAIDS in Russia. In addition, the data in the IHME and Eurostat databases (or similar databases) are only as good as those data provided by countries and will have their own limitations, such as incomplete datasets or out-dated data.

The following section provides a brief overview of first, key multi-country data on mortality, morbidity and risks factors among women in the 53 countries of the WHO European region, and secondly, data on education, economic resources and labour conditions and their impact on health. These examples were selected to il- 


\section{Table 1. Description of the main Database Consulted.}

\section{Database}

European Health for All database (HFA-DB)

European Commission

Directorate-General Eurostat (Eurostat)
Institute for Health Metrics and Evaluation (IHME) Global Burden of Disease (GBD)

\section{Scope}

Provides a selection of core health statistics covering basic demographics, health status, health determinants and risk factors, and health-care resources, utilization and expenditure in the 53 countries in the WHO European Region. Allows queries for country, intercountry and regional analyses, and displays the results in tables, graphs or maps, which can be exported for further use (HFA-DB 2016)

Provides a comprehensive selection of core statistics in the 28 countries of the European Union. Allows queries for country, intercountry and regional analyses, and displays the results in tables, graphs or maps, which can be exported for further use. Users can download individual datasets by extracting data directly from the database, by selecting our most popular tables from the homepage, by using our bulk download facility or via web services.

Provides a comprehensive picture of what disables and kills people across countries, time, age and sex. The Global Burden of Disease (GBD) provides a tool to quantify health loss from hundreds of diseases, injuries and risk factors, so that health systems can be improved and disparities eliminated (IHME 2017).

Provides a comprehensive selection of statistics covering 35 countries worldwide. Allows queries for country, intercountry and regional analyses, and displays the results in tables, graphs or maps, which can be exported for further use (OECD 2016).
Organization for Economic Cooperation and Development database $(\mathrm{OECD})$ 


\section{Data compilation}

The data are compiled from various sources, including country experts, WHO/Europe's technical programmes and partner organizations, such as agencies of the United Nations system, the statistical office of the European Union (EUROSTAT) and the Organisation for Economic Cooperation and Development. (HFA-DB 2016).

Eurostat does not collect data. This is done by the statistical authorities of member states. They verify and analyse national data and send them to Eurostat. Eurostat's role is to consolidate the data and ensure they are comparable, using harmonized methodology. Eurostat is actually the only provider of statistics at the European level, and the data we issue are harmonized as far as possible (Eurostat 2016).

Collected and analysed by a consortium of more than 2,300 researchers in more than 130 countries, the data capture premature death and disability from more than 300 diseases and injuries in 195 countries by age and sex from 1990 to the present, allowing comparisons over time, across age groups and among populations (IHME 2017).

Collected, analysed and discussed for decision-making and implementation followed by peer review and multilateral surveillance

(OECD 2016).

\section{Update and accessibility}

HFA-DB is updated twice a year and can be used online or downloaded for work on a personal computer (HFA-DB 2016).

All European statistics are available from the database on Eurostat's website. A large range of Eurostat data is also accessible on different mobile apps. Eurostat's database always contains the latest version of the datasets. Datasets are updated twice a day, at 11 am and 11 pm (Eurostat 2016).

The flexible design of the GBD machinery allows for regular updates as new data and epidemiological studies are made available. In this way, the tools can be used at the global, national and local levels to understand health trends over time (IHME 2017).

All European statistics are available from the database on the OECD website. OECD data always contain the latest version of the datasets. 
lustrate the outcome information that can be obtained using the open-access databases described above that are related to the most important socioeconomic determinants of women's health. Furthermore it shows the relevant multi-country information that can be accessed online and free of charge, and without the need to use complex software statistical programs. Even though the databases are free of access and easy to use, they provide enough trustworthy and reliable information to raise awareness and encourage the implementation of policy measures targeted at improving women's health across a large number of countries.

\section{DATA ON MORTALITY, MORBIDITY AND RISK FACTORS}

Using the European Health for All database (HFA-DB), it was found that in the 53 countries in the WHO European region, life expectancy among women increased in all countries but one from 2000 to 2015 . However, this increase is unevenly distributed throughout the region, with a fifteen-year difference between countries (WHO 2016b), highlighting the still persistent inequalities among European women. Furthermore, a higher life expectancy does not imply that all the additional years are lived in good health. Data from 2013 show that, even in European countries with the highest life expectancy, women spent almost twelve years of their lives in ill health (WHO 2016a).

Through access to the Global Burden of Disease data-base from IHME, it was identified general trends for all women stratified by age groups. This shoved that the greatest mortality burden for women in Europe is due to cardiovascular diseases and cancer, while the great burden of morbidity between the ages of 18 and 49 is due to mental health, musculoskeletal and neurological disorders and cancers. Mental ill health is a major concern that already affects women in early adolescence and throughout the life-course, irrespective of country of residence, with rates of mental ill health steadily increasing for all women (IHME 2016). Among the main risk factors associated with these causes of death and morbidity, we find alcohol use, tobacco-smoking, high blood pressure, high body mass index and high household air pollution (IHME 2016). The first three mortality risks for young women aged 15-19 are alcohol use, intimate partner violence and drug use (IHME 2016). Multi-country data on obesity show that these risk factors have been rapidly increasing throughout the region over the last four years, with prevalence ranging from $16 \%$ in Austria to $36 \%$ in Turkey (WHO 2015).

\section{DATA ON EDUCATION, ECONOMIC RESOURCES AND LABOUR CONDITIONS AND THEIR IMPACT ON HEALTH}

Using the OECD data on education, income and working conditions may give us insights into the socioeconomic determinants of gender differences. For example, persistent differences related to education was found. Although girls and boys in $\mathrm{Eu}^{-}$ rope have equal access to pre-primary, primary and secondary education, and women outnumber men in secondary and/or tertiary education in several countries (OECD 2015), women do not always maximize their investment in education as men do, with men having a higher labour force participation in 48 European countries (UNDP 2013a, 2013b). Moreover, most countries in the region show a considerable difference in women's self-perceived health based on education or income. Eurostat data show that $48.8 \%$ of women aged 1664 years with pre-primary or lower secondary education report good or very good health, compared to $69 \%$ of women with upper- or post-secondary education and $81.3 \%$ with a tertiary education (Eurostat 2016). 
The impact of income and wealth on women's health and well-being is well established. Unequal access for women to wages, pensions and social transfers has health and social consequences (OECD 2012; UNDP 2016). Linking life-expectancy to income shows that generally, the higher the income of the population, the longer one's life will be (WHO 2014). Moreover, pay gaps and pension gaps persist in all countries (Eurostat 2015; OECD 2016). Although the gender pay gap has generally declined in the last decade, women in the EU earn about 16\% per hour less, even when their qualifications are as good as, or better than, their male counterparts (Eurostat 2012). Sectors dominated by women have lower salaries that those dominated by males (ILO, 2016), with the pay gap usually higher in the private sector than in the public sector. No country in the region has achieved wage equality for similar work.

Despite increases in women's labourforce participation in the WHO European region, therefore, women remain disadvantaged. They continue to be engaged in the workforce less than men, are more involved in unpaid work such as care-givers, work in jobs that tend not to have contracts or with only short-term contracts, are underrepresented in senior management and decisionmaking positions, earn less than men and are more likely to end their lives in poverty (OECD 2012; UNDP 2016; OECD 2016). The UNDP 2016 Gender Inequality Index shows that average labour-force participation in the European Region was $45.6 \%$ for women (compared to $70 \%$ for men), and that only 32 countries had a women's labour-force participation greater than 50\% (UNDP 2016). Data from OECD countries reveal that in 2014, 73\% of men aged 15-64 years were in full-time employment, compared to $51 \%$ of women in the same age group (OECD 2016). Inequalities linked to ethnicity, migrant status and disability are evident in employment and working conditions. Minorities face barriers to labour-market access, encounter discrimination and are overrepresented in informal employment. Higher levels of unemployment and poorer working conditions (sometimes linked to lower levels of education) are reported among Roma women in some European countries (UNECE 2015).

Research on work-related diseases does not include women to the extent it should, although some progress has been made in relation to cancer and reproductive issues. It is often based on knowledge of maledominated professions and male metabolism of chemicals, and excludes part-timers and occupations for which little is known about exposures. Musculoskeletal disorders and stress-related problems affect women more than men $(60 \%$ and $16 \%$, respectively) (Europe.eu/social 2015).

These are just some examples of the information that can be obtained by accessing multi-country open-access data sets containing sex-disaggregated information. Although women's health across Europe has improved during the last ten years, there are differences between countries and within countries that need to be addressed. Moreover, data on education, income and labour conditions show that there is still a long way to go, for example, to maximize women's gains from their investment in education.

\section{GENDER TRANSFORMATIVE HEALTH POLITICS}

In this article, it is shown what can be done by having access to and making use of open-access multi-country sex-disaggregated data from a variety of sources and sectors across a group of countries belonging to the WHO European region. This argues in favour of this type of data vs. restrictive big data that are often only available for a very specific sub-sample of countries and are generally managed by resource-intense 
research institutions for payment. For the purposes of this article, it provides important evidence for the state of play of women's health across the life-course in the wider WHO European region. This provided quantitative insight into differences between men and women within the region, as well as differences among women across it. In some cases the available data (e.g. Eurostat) were cross-linked with key social determinants such as place of residence, wealth quintile, level of education and/or employment status to provide some quantitative insight into inequalities in health among the women within a country.

However, this work showed that on-going efforts are still needed to ensure that more systematic collection of sex-disaggregated data continues across all 53 European countries, and that countries analyse, make use of and disseminate findings. In addition, the work underlined the need for sex-disaggregated data to be complemented by disaggregation on grounds of disability, ethnic origin, level of education, place of residence, sexual orientation and gender identity so that health policies can better address gender inequalities and inequalities among women (WHO 2016a). However, this type of information should be collected through anonymous surveys and not on an individual basis, as it should be argued that this information is too sensitive to be collected on an individual, personalized basis. Again, open-access data gathered in this way would be safer than big data.

Large sex-disaggregated open-access data provides several benefits for shaping health policies that benefit all women equally with regard to their different and changing needs across the life-course and beyond a focus on maternal health. The availability of such data is a prerequisite for fostering progressive changes in power relationships between women and men, and addressing the causes of gender-based health inequalities. Together with building evidence for the development of policies and programs, it also allows cross- and within-country comparison. If this information is analysed and used, it can facilitate the development and adoption of policies that are potentially gender-transformative for both women and men at the national or sub-national levels. Where linked to key social determinants, such data enable policies to be developed that not only incorporate gender equality but can also address inequalities in health among women. Openaccess data also facilitate the systematic monitoring of trends and specific issues over time such as changes in health behaviour among women, outcomes from cardiovascular care and linked issues such as access to education, a reduction in the pension gap and/or women's access to economic resources, all of which affect health outcomes.

Despite these limitations, the review of the IHME database enabled refinement of the issues to be covered in order to obtain a reasonable overview of the main mortality and morbidity issues for women across the life-course within the WHO European region. This provided an important springboard for identifying gaps in available sexdisaggregated data as well as data that can be cross-linked with key social, economic, environmental and cultural determinants. It also highlighted how previous claims that such data were not available and/or not good enough were not really well-founded. This work for the report highlighted how much data is actually available and how researchers as well as policy-makers need to make better use of it.

Open access sex-disaggregated data is a valuable tool for unveiling and monitoring gender inequalities in health, as well as inequalities among women across a wide range of countries and within countries with regard to social factors. In doing so, it serves as a tool to inform policies and programmes aiming at reducing inequalities in health. Constant efforts are needed to collect data disaggregated not only by sex and 
gender, but also by ethnic origin, levels of education, place of residence, sexual orientation and gender identity so that policies can address gender inequalities and inequalities among women.

\section{Notes}

1. Albania, Andorra, Armenia, Austria, Azerbaijan, Belarus, Belgium, Bosnia and Herzegovina, Bulgaria, Croatia, Cyprus, Czech Republic, Denmark, Estonia, Finland, France, Georgia, Germany, Greece, Hungary, Iceland, Ireland, Israel, Italy, Kazakhstan, Kyrgyzstan, Latvia, Lithuania, Luxemburg, Malta, Monaco, Montenegro, Netherlands, Norway, Poland, Portugal, Republic of Moldova, Romania, Russian Federation, San Marino, Serbia, Slovakia, Slovenia, Spain, Sweden, Switzerland, Tajikistan, The former Yugoslav Republic of Macedonia, Turkey, Turkmenistan, Ukraine, United Kingdom, Uzbekistan.

2. One DALY can be thought of as one lost year of 'healthy' life. The sum of these DALYs across the population, or the burden of disease, can be thought of as a measurement of the gap between current health status and an ideal health situation in which the entire population lives to an advanced age, free of disease and disability. See http://www.who.int/healthinfo/global_burden_disease/metrics_daly/en/

\section{REFERENCES}

- Cantarero-Arévalo, L.; Michaud, P.A.; Sethi, D.; Ferry, T.; Baltac, V. \& Yordi, I. (2011): Evidence for gender responsive actions to prevent violence: young people's health as a whole-of-society response. World Health Organization, Regional Office for Europe, 2011.

- Cantarero-Arévalo, L; Ersbøll, Annette Kjaer; Holstein, Bjørn E; Andersen, Anette; Kaae, Susanne \& Hansen, Ebba Holme (2014): Ethnic and migrant differences in the use of anti-asthmatic medication for children: the effect of place of residence, in: Pharmacoepidemiology and Drug Safety 2014/23(1): 95-104.

- Data2x (2017): Gender Data Gaps. (Available at: http://data2x.org/what-is-gender-data/genderdata-gaps/9, accessed May 2017).

- Europe.eu/social (2015): Analysis note. Men and gender equality: tackling gender segregated family roles and social care jobs. Brussels: European Commission Directorate-General for Employment, Social Affairs and Equal Opportunities, 2010 (Available at:

http://ec.europa.eu/social/BlobServlet?docId $=5$ 532\&langId =en, accessed 20 July 2015).

- Europe.eu/social (2009): Report on equality between women and men 2009. Brussels: European Commission Directorate- General for Employment, Social Affairs and Equal Opportunities, 2009 (Available at:

http://ec.europa.eu/social/main. jsp? catId=738\&langId=en\&pubId=86\&further-

Pubs $=y e s$, accessed 20 July 2015).

- Eurostat (2014): Self-perceived health by sex, age and educational attainment level [online database]. Luxembourg: Eurostat, 2014 (Available at:

http://ec.europa.eu/eurostat/web/health/health -status-determinants/data/database, accessed 20 July 2016).

- Eurostat (2015): People at risk of poverty or social exclusion [online database]. Luxembourg: Eurostat, 2015 (Available at : http://ec.europa. eu/eurostat/web/products-datasets/-/t2020_50, accessed 20 July 2016).

- Eurostat (2016): Database. In: Income and living conditions. Data [online database]. Luxembourg: Eurostat; 2016 (Available at: http:// ec.europa.eu/eurostat/web/income-and-livingconditions/data/database, accessed 20 July 2016).

. Gurin (2016): What is open data? (Available at: http://opendatahandbook.org/guide/en/whatis-open-data/, accessed January 2016).

- Hilbert (2016). Big data for development: a review of promises and challenges, in: Dev Policy Rev, 2016.

- HFA-DB (2017): European health for all database [online database]. Copenhagen: WHO Regional Office for Europe, 2015 (Available at: http:// www.euro.who.int/en/data-and-evidence/databases/european-health-for-alldatabase-hfa-db, accessed 20 July 2016). - IHME (2017): Institute for Health Metrics and Evaluation [online database]. Seattle. (Available at: http://www.healthdata.org/gbd/about, accessed 20 July 2016).

- ILO (2016): Women at work: trends 2016. Geneva: International Labour Office, 2016. (Available at: http://www.ilo.org/wcmsp5/groups/public/—-dgreports/—-dcomm/--publ/documents/publication/wcms_457317.pdf, accessed 20 June 2016). 
. Mittelstadt, B.D. \& Floridi, L. (2016): The ethics of big data: current and foreseeable issues in biomedical contexts, in: Science and Engineering Ethics, 2016/22 (2): 303-341.

- OECD (2012): Gender equality in education, employment and entrepreneurship: final report to the MCM 2012. Paris: Organisation for Economic Cooperation and Development, 2012 (Available at: https://www.oecd.org/

employment/50423364.pdf, accessed 20 July 2016).

- OECD (2015): In it together: why less inequality benefits all. Paris: Organisation for Economic Cooperation and Development, 2015 (Available at: http://www.oecd.org/social/in-it-together-whyless-inequality-benefits-all-9789264235120en.htm, accessed 20 July 2016).

. OECD (2016): Time spent in unpaid, paid and total work, by sex, in: Gender equality [online database]. Paris: Organisation for Economic Cooperation and Development, 2016 (Available at: http://www.oecd.org/gender/data/ timespentinunpaidpaidandtotalworkbysex.htm, accessed 20 July 2016).

- UNDP (2013a): Mean years of schooling (females aged 25 years and above) (years), in: UNDP buman development reports [online database]. New York (NY): UNDP, 2013 (Available at:

http://hdr.undp.org/en/content/mean-yearsschooling-females-aged-25-years-and-above-years, accessed 20 July 2016).

. UNDP (2013b): Expected years of schooling, females (years), in: UNDP human development reports [online database]. New York (NY): UNDP, 2013 (Available at: http://hdr.undp.org/en/content/expected-years-schooling-females-years, accessed 20 July 2016).

. UNDP (2016): Table 5: gender inequality index, in: UNDP human development reports [online database]. New York (NY): United Nations Development Programme, 2016 (Available at: http://hdr.undp.org/en/composite/GII, accessed 20 July 2016).
. UNECE (2015): Indicators of gender equality. Geneva: UN Economic Commission for Europe, 2015 (Available at: http://www.unece.org/ fileadmin/DAM/stats/publications/2015/ECE_ CES_37_WEB.pdf, accessed 20 July 2016). . UN WOMEN (2016): Gender Mainstreaming. (Available at: http://www.un.org/womenwatch/osagi/gendermainstreaming.htm, accessed May 2017).

. UN WOMEN (2017a): Equal pay for work of equal value. Available at: (http://www.unwomen.org/en/news/in-focus/csw/equal-pay, accessed May 2017).

. UN WOMEN (2017b): Gender Equality Glosary. UN Women Training Centre. (Available at: https://trainingcentre.unwomen.org/mod/glossary $/$ view.php?id=36\&mode $=$ letter\&hook=G\&sor tkey $=\&$ sortorder $=$, accessed May 2017).

- WHO (2011): WHO Gender mainstreaming for health managers: a practical approach. Geneva: World Health Organization, 2011.

-WHO (2014): Gender, climate change and health. Geneva: World Health Organization, 2014. (Available at: http://www.who.int/ globalchange/publications/reports/gender_climate_change/en/, accessed 20 July 2016).

-WHO (2015): Beyond the mortality advantage: investigating women's health in Europe. Copenhagen: WHO Regional Office for Europe, 2015. - WHO (2016a): Women's health and well-being in Europe: beyond the mortality advantage. Copenhagen: WHO Regional Office for Europe, 2016. - WHO (2016b): European Health for All database. (Available at:

http://www.euro.who.int/en/data-and-evidence/databases/european-health-for-all-familyof-databases-hfa-db, accessed May 2017).

- Zhang, Xinzhi, et al. (2017): Big Data Science: Opportunities and Challenges to Address Minority Health and Health Disparities in the 21st Century, in: Ethnicity \& Disease, 2017/27(2): 95-106. 